\title{
Energy devices for pulmonary artery sealing in video-assisted thoracoscopic surgery (VATS) segmentectomy: literature review and surgical technique
}

\author{
Amit Katz, Moishe Liberman \\ Division of Thoracic Surgery, CHUM Endoscopic Tracheobronchial and Oesophageal Center, University of Montréal, Montréal, Québec, Canada \\ Contributions: (I) Conception and design: Both authors; (II) Administrative support: Moishe L; (III) Provision of study materials or patients: Moishe \\ L; (IV) Collection and assembly of data: Moishe L; (V) Data analysis and interpretation: Both authors; (VI) Manuscript writing: Both authors; (VII) \\ Final approval of manuscript: Both authors. \\ Correspondence to: Moishe Liberman. Division of Thoracic Surgery, CHUM Endoscopic Tracheobronchial and Oesophageal Center, University of \\ Montréal, Montréal, Québec, Canada. Email: moishe.liberman@umontreal.ca.
}

\begin{abstract}
Objective: To review the application of energy devices for pulmonary vessel sealing and to share our experience using these devices in anatomical segmentectomy.

Background: Due to recent advances in diagnostic technology and the widespread application of lung cancer screening, anatomical segmentectomy has become a popular option for the definitive treatment of early-stage lung cancer. This procedure requires dissection, manipulation and ligation of relatively small pulmonary vessels. The most common reason for emergent conversion of video-assisted thoracoscopic surgery (VATS) anatomical segmentectomy to open thoracotomy is pulmonary vascular injury that happened during the dissection or the manipulation that is required when using endostaplers. Energy sealing devices have a small footprint, which potentially can reduce the risk of vessel injury during surgery.

Methods: In this paper, we systematically searched the literature for animal studies, Ex vivo models, and retrospective and prospective studies, reporting on the results of the use of energy devices for pulmonary vessel sealing. We also shared our experience in using these devices in anatomical segmentectomy.

Conclusions: Energy devices for pulmonary vascular sealing of vessels $7 \mathrm{~mm}$ or less is both feasible and safe. The learning curve for experienced VATS surgeon is relatively short, and it significantly aids in simplifying minimally invasive segmentectomy.
\end{abstract}

Keywords: Video-assisted thoracoscopic surgery (VATS); pulmonary artery sealing; energy devices; LigaSure; Harmonic

Received: 15 June 2021; Accepted: 08 November 2021; Published: 20 October 2022.

doi: 10.21037 /jovs-21-38

View this article at: https://dx.doi.org/10.21037/jovs-21-38

\section{Introduction}

Anatomical lung resection, including lobectomy and segmentectomy are the preferred surgical treatment for early-stage lung cancer (1). Lobectomy is still considered the standard of care for the surgical treatment of resectable lung cancer, however, sublobar resection for small, non-hilar lesions is gaining popularity and the literature is rapidly evolving. Recent advances in diagnostic technology and the widespread application of low-dose helical computed tomography for lung cancer screening have increased the detection of small lung tumors, and therefore anatomical segmentectomy has become a popular option for patients with both poor lung function and early-stage disease (2). Video-assisted thoracoscopic surgery (VATS) or robotic assisted thoracic surgery (RATS) are the preferred surgical approaches in most patients (3).

During any anatomical lung resection, the ligation of small pulmonary vessels is challenging and pulmonary 
vascular injury is the most common reason for emergent conversion to open thoracotomy (4). The technical difficulty and danger are related to vessel dissection, manipulation, stapling, and division that is required when using endostaplers. Energy sealing devices have a smaller footprint than endostaplers and when using these devices, there is less manipulation and dissection required on the pulmonary vasculature. This consequently reduces the risk of iatrogenic vessel injury. In this paper we will review the application of pulmonary vessel sealing using energy devices in anatomical segmentectomy. We present the following article according to the Narrative Review reporting checklist (available at https://jovs.amegroups.com/article/ view/10.21037/jovs-21-38/rc).

\section{Methods}

We searched PubMed for all studies (2000 to 2021) published in English that report results relating to the use of energy devices for sealing pulmonary vessels in animal studies, ex vivo models, retrospective and prospective studies by using the terms: energy devices for VATS or energy devices for pulmonary artery (PA) sealing or energy devices for pulmonary vessels sealing. In our summary table (Table 1) we included only animals or prospective studies.

\section{Energy sealing devices in anatomical lung resection}

Energy sealing device, such as electrothermal bipolaractivated devices or ultrasonic systems, are widely used in various kinds of surgeries. These instruments are used to achieve adequate hemostasis and safe and easier tissue dissection. The two devices that have been studied in largescale prospective trials include LigaSure and Harmonic. LigaSure $^{\mathrm{TM}}$ (Medtronic, Minneapolis, MN, USA) is an electrothermal device utilizes a combination of pressure and continuous bipolar energy to denatures the collagen and elastin of vessel walls in order to create vessel fusion. Harmonic Ace ${ }^{\circledR}$ (Ethicon Endo-Surgery, Inc., Ohio, USA), uses ultrasonic vibration allowing for the effects of proteins denaturation and coagulation. The two devices are used to seal vessels up to $7 \mathrm{~mm}$ in diameter and include a feedbackcontrolled system that automatically stops energy delivery once the seal cycle is complete.

Recently, LigaSure and Harmonic have been tested for sealing pulmonary vessels (Table 1). In an animal model the two devices were found to be safe for sealing a pulmonary vessel smaller than $7 \mathrm{~mm}(5,9)$. In human ex vivo $\mathrm{PA}$ sealing model, the mean bursting pressure of ultrasonic devices was twice as high as bipolar devices (Harmonic $416 \mathrm{mmHg}$, LiGasure 215 mmHg, EnSeal $134 \mathrm{mmHg}$ ) (12). In animal model, the mean tissue temperatures during PA sealing is about the same in ultrasonic and bipolar devices $\left(70-78{ }^{\circ} \mathrm{C}\right)$ but the instrument blade temperature is much higher in ultrasonic devices $\left(224\right.$ vs. $\left.83^{\circ} \mathrm{C}\right)(18)$.

In histological and immunohistochemical analysis of pulmonary vessels divided by LigaSure, it was found that LigaSure sealing result in sealing of the adventitia only, without complete fusion of the layers of the PA walls. It remains unclear whether these findings have a clinical impact $(6,7)$. As a first step for using energy devices in anatomical lung resections, the proximal side of the pulmonary branch were ligated and just after sealed and divided with the devices $(10,11)$. Recently, Okada et al. published a prospective study that evaluated the safety of using LigaSure for sealing pulmonary vessels as large as $7 \mathrm{~mm}$ during anatomic lung resection, with no additional reinforcing material such as suture ligation or clips. A postoperative hemorrhage occurred in the 128th case, and as a result, they reduced the maximum size of sealing for PAs to $5 \mathrm{~mm}$ and completed 200 anatomical resections with no further postoperative hemorrhage (8).

Our group conducted a step-by step approach to demonstrate the efficacy and safety of the Harmonic scalpel for sealing pulmonary vessels of $7 \mathrm{~mm}$ or less in diameter. In ex vivo models we evaluated the burst pressures of PA branches sealed using different sealing methods. It was found that PAs sealed with ultrasonic energy can sustain higher pressures compared with advanced bipolar energy devices or endostaplers, without seal failures $(12,13)$. In an animal survival study, 10 lobectomies were completed using Harmonic without any bleeding complication at 30 days (14). Then in two sequential phase 1 clinical trials we evaluated the safety of using Harmonic for PA sealing in open and VATS lobectomy $(15,16)$. Recently, we completed a multicenter, international prospective trial in which PA branches of $7 \mathrm{~mm}$ or less were sealed and divided with Harmonic. In this study 139 patients underwent lobectomy, and 11 patients segmentectomy, performed by 15 surgeons; 12 of these surgeons had never used Harmonic on pulmonary vessels and learned the technique specifically for the trial. A total of $239 \mathrm{PA}$ branches were divided with Harmonic, 181 with endostaplers, and 4 with endoscopic clips. Intraoperative bleeding occurred in $3(1.3 \%)$ of the PA branches divided with Harmonic and 4 (2.2\%) PA branches 
Table 1 Summary of published studies on pulmonary vessel sealing using energy devices

\begin{tabular}{llll}
\hline Author & Device & Type of study & Main findings \\
\hline Lacin et al. & LigaSure & Animal study & Twelve sheep underwent lobectomy. All of the vessels were \\
& sealed and divided with LigaSure. In 6 cases of right lower \\
& lobectomy, following vascular division, ephedrine was injected \\
& & to increase PAP, and in 6 right upper lobectomy cases, animals \\
& were followed and euthanized at 7 days. Dehiscence rate after \\
& the increasing of PAP, was $2 / 6$ in PAs and $3 / 6$ in PVs larger than \\
& $9 \mathrm{~mm}$. No early or late hemorrhage was seen without ephedrine \\
& injection. Overall, no vascular complications were observed in \\
& vessels less than $7 \mathrm{~mm}$ in diameter
\end{tabular}

Lesser et al. LigaSure Prospective In 30 cases of open lobectomy, 15 PAs diameter, 3-5 mm, and 2013, (6) study

Yoshiya et al. LigaSure 2018, (7)

Prospective study

Okada et al. LigaSure 2019, (8)

Prospective study

Nicastri et al. Harmonic 2007, (9)

Tanaka et al. Harmonic 2009, (10)

Toishi et al. Harmonic, 2014, (11) EnSeal, LigaSure

In 30 cases of open lobectomy, 15 PAs diameter, $3-5 \mathrm{~mm}$,
15 PAs $6-8 \mathrm{~mm}$, were divided with LigaSure, and the same number and size of PAs were suture ligated. After LigaSure sealing the mean burst pressure of PAs $3-5$ and $6-8 \mathrm{~mm}$ was 4.3- and 6.4-fold less than after ligation. In histologic examination, fusion of the adventitia only, was demonstrated in all LigaSure sealing cases

LigaSure was used for sealing of $22 \mathrm{PAs}$ and $21 \mathrm{PVs}(2-7 \mathrm{~mm})$. Histological findings and thermal damage of the sealed vessels were evaluated. In all divided PAs, a wide area of thermal necrosis and fusion of the adventitia only was documented. Conversely, the wall layers of all divided PVs were completely fused

In 328 patients, 466 PAs and 402 PVs were sealed. Due to a post-operative PA bleed the study protocol was changed midway and the maximum size of PA sealed with LigaSure was reduce from 7 to $5 \mathrm{~mm}$. Overall postoperative hemorrhage rate was $0.3 \%$ (1/328 patients)

Animal model Lobectomies were performed in 9 pigs. Vascular sealing with Harmonic was successful in all arteries $5 \mathrm{~mm}$ or less and veins $7 \mathrm{~mm}$ or less

Prospective cohort study and animal model

In 20 patients who underwent VATS anatomical lung resection, $43 \mathrm{PAs}$ and $13 \mathrm{PVs} 5 \mathrm{~mm}$ or less were secured with a proximal single ligation and divided with Harmonic. Vascular sealing was successful in all except two early procedures. There was no postoperative bleeding. In pig model, the bursting pressure of sealed PAs was $>75 \mathrm{mmHg}$

Randomized A total of 58 patients underwent lobectomy were randomly controlled allocated to a control group $(n=14)$ and to VSD group $(n=44)$, study which comprised three sub-groups: EnSeal $(n=17)$, LigaSure $(n=15)$ and Harmonic $(n=12)$. In the VSD groups, the proximal side of PA stumps ( $\leq 7-\mathrm{mm}$ diameter) were ligated and then divided and sealed with respective devices, and in the control group ligated only. The burst pressure of ligation-treated PA stumps was higher than that of VSD-treated stumps. However, the burst pressure for all groups was sufficient to withstand the physiological PA pressure, with no significant differences between the different energy devices. The VSD group demonstrated reduced intraoperative blood loss, surgeon stress, postoperative drainage volume and duration
Conclusion

LigaSure can be used for sealing in pulmonary vessels less than $7 \mathrm{~mm}$

The burst pressure of PA after sealing with LigaSure is significantly less compared with suture ligation, and does not result in complete fusion of the artery layers

It remains unclear whether the incomplete fusion and thermal necrosis of the PAs sealed with LigaSure constitute a clinical risk

Study was changed midway due to a post-operative PA bleed

Harmonic is a reliable device to divide PAs and PVs s smaller than 5 and $7 \mathrm{~mm}$ respectively

Pulmonary vessels can be safely divided using the Harmonic with proximal single ligation

VSD is simple and safe to use in sealing of PA $7 \mathrm{~mm}$ or less when the proximal side is ligated

Table 1 (continued) 
Table 1 (continued)

\begin{tabular}{|c|c|c|c|c|}
\hline Author & Device & Type of study & Main findings & Conclusion \\
\hline $\begin{array}{l}\text { Liberman } \\
\text { et al. } 2015 \text {, } \\
\text { (13) }\end{array}$ & Harmonic & $\begin{array}{l}\text { Prospective } \\
\text { cohort study, } \\
\text { human ex vivo } \\
\text { model }\end{array}$ & $\begin{array}{l}\text { In specimens from } 43 \text { patients, } 90 \text { vessels were sealed with } \\
\text { Harmonic and } 47 \text { were sealed with vascular endostapler. The } \\
\text { mean PA branch diameter was } 6 \mathrm{~mm} \text {. The mean burst pressure } \\
\text { was } 333 \mathrm{mmHg} \text { in the Harmonic group and } 114 \mathrm{mmHg} \text { in } \\
\text { the endostapler group. There were no sealing failures in the } \\
\text { harmonic group }\end{array}$ & $\begin{array}{l}\text { PA branches sealed using } \\
\text { the Harmonic were able to } \\
\text { sustain high intraluminal } \\
\text { pressures. These pressures } \\
\text { were equal to or greater than } \\
\text { the stapled vessels }\end{array}$ \\
\hline $\begin{array}{l}\text { Goudie et al. } \\
2016,(14)\end{array}$ & Harmonic & $\begin{array}{l}\text { Animal } \\
\text { survival study }\end{array}$ & $\begin{array}{l}\text { Ten dogs underwent VATS right upper }(n=5) \text { and right lower } \\
(n=5) \text { lobectomy. Harmonic was used to seal } 21 \text { PA branches. } \\
\text { No PA branch was divided with an endostapler. One 10-mm } \\
\text { PA branch had a partial seal failure immediately at the time of } \\
\text { sealing. The device was reapplied on the stump, and the PA } \\
\text { branch was successfully sealed. All dogs survived } 30 \text { days, with } \\
\text { no postoperative bleeding }\end{array}$ & $\begin{array}{l}\text { In an animal survival model, } \\
\text { the use of Harmonic for } \\
\text { PA branch sealing in VATS } \\
\text { lobectomy is safe and } \\
\text { effective }\end{array}$ \\
\hline $\begin{array}{l}\text { Goudie et al. } \\
2017,(15)\end{array}$ & Harmonic & $\begin{array}{l}\text { Prospective } \\
\text { phase } \\
1 \text { clinical trial }\end{array}$ & $\begin{array}{l}\text { In } 10 \text { patients who underwent open lobectomy, a total of } \\
14 \text { PAs were sealed with Harmonic. The mean vessel } \\
\text { diameter was } 5 \mathrm{~mm} \text { (range, } 2-7 \mathrm{~mm} \text { ). There was no intra- or } \\
\text { postoperative bleeding related to ultrasonic PA sealing }\end{array}$ & $\begin{array}{l}\text { In open lobectomy, PA } \\
\text { sealing for vessels } 7 \mathrm{~mm} \\
\text { or less was safely achieved } \\
\text { with Harmonic }\end{array}$ \\
\hline $\begin{array}{l}\text { Goudie et al. } \\
2018,(16)\end{array}$ & Harmonic & $\begin{array}{l}\text { Prospective } \\
\text { phase } \\
1 \text { clinical trial }\end{array}$ & $\begin{array}{l}\text { In } 20 \text { patients who underwent VATS lobectomy, } 31 \text { branches of } \\
7 \text { mm or less were sealed and divided with Harmonic, } 24 \text { with } \\
\text { endostaplers, } 2 \text { with clips, and } 1 \text { with sutures. No intraoperative } \\
\text { or postoperative bleeding was related to PA branch sealing with } \\
\text { Harmonic }\end{array}$ & $\begin{array}{l}\text { In VATS lobectomy, PA } \\
\text { branch sealing for vessels } \\
7 \mathrm{~mm} \text { or less was safely } \\
\text { achieved using Harmonic }\end{array}$ \\
\hline $\begin{array}{l}\text { Goudie et al. } \\
2020,(18)\end{array}$ & $\begin{array}{l}\text { Harmonic, } \\
\text { Sonicbeat, } \\
\text { Thunderbeat, } \\
\text { EnSeal }\end{array}$ & Animal model & $\begin{array}{l}\text { Different types of VSD were used for sealing } 37 \text { PA branches } \\
\text { were sealed in } 4 \text { pigs. The mean tissue temperatures at the } \\
\text { site of the sealing measured with a thermal camera were } 78 \text {, } \\
75,70 \text { and } 82{ }^{\circ} \mathrm{C} \text {, and the mean instrument blade temperatures } \\
\text { were } 224,195,83 \text { and } 170^{\circ} \mathrm{C} \text { for the Harmonic and Sonicbeat, } \\
\text { EnSeal, and Thunderbeat, respectively. The mean diameter of } \\
\text { the region with tissue reaching } 60^{\circ} \mathrm{C} \text { or more measured with the } \\
\text { thermal camera was between } 4 \text { and } 6 \mathrm{~mm} \text { for the } 4 \text { devices }\end{array}$ & $\begin{array}{l}\text { Instrument blades can reach } \\
\text { very high temperatures that } \\
\text { may cause tissue damage } \\
\text { during and immediately } \\
\text { following activation. A 3-mm } \\
\text { safety margin between the } \\
\text { instrument blades and vital } \\
\text { structures is recommended }\end{array}$ \\
\hline
\end{tabular}

PA, pulmonary artery; PAP, pulmonary artery pressure; PV, pulmonary veins; VATS, video-assisted thoracoscopic surgery; VSD, vascular sealed devices.

divided with endostaplers. There was no postoperative bleeding from divided PA branches with either sealing method. This study proved that ultrasonic energy is safe for sealing a pulmonary arteries $7 \mathrm{~mm}$ or less (17).

\section{Surgical technique for pulmonary vessel sealing using energy devices}

LiGasure and Harmonic are widely used in thoracic 


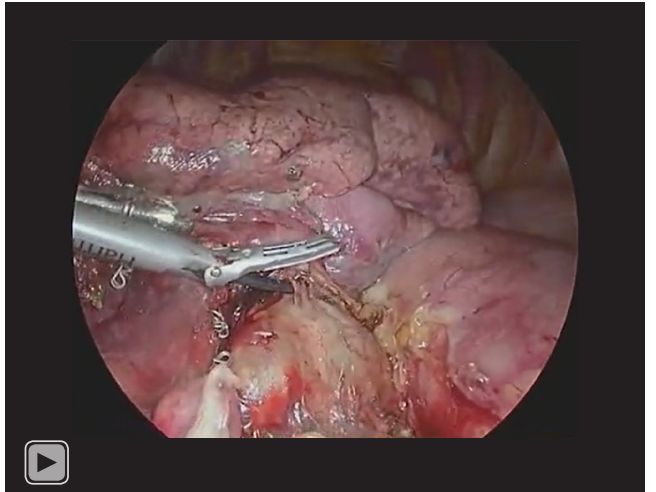

Video 1 A video of left superior anatomical segmentectomy. Harmonic Scalpel was used for lymph node dissection and pulmonary artery branch sealing. A pulmonary artery $>7 \mathrm{~mm}$ and the segmental bronchus were sealed with endostaplers. The segment border was marked with indocyanine green.

surgery. The surgical technique using these two instruments is slightly different (Harmonic allows more sharp dissection while LiGasure requires more blunt dissection technique), but in our experience, the adjustments required to switch from one to the other is simple and needs a short learning curve. In our practice, we use Harmonic routinely in lobectomies and segmentectomies for lymph node and hilar dissection and for the sealing of pulmonary vessels equal to or less than $7 \mathrm{~mm}$. As we mentioned previously, there is also limited data to support the use of advanced bipolar energy for sealing pulmonary vessels, however, the safety data from multiple well designed and sequential safety and efficacy studies for ultrasonic energy use with the Harmonic scalpel is stronger and more mature.

We usually use the harmonic scalpel for sealing of the following branches: posterior ascending arteries of the right upper lobe (RUL) and left upper lobe (LUL), right middle lobe (RML) arteries, superior segmental branch in right lower lobe (RLL) and left lower lobe (LLL). The number of pulmonary arterial branch to the LUL vary from 2 to 7, we usually use the Harmonic for the lingular arteries and for a small posterior segmental branch of the LUL. Harmonic sealing of the PA and segmental veins is ideal for most segmentectomies and in many cases we perform lingulectomy, apicoposterior, and superior segmentectomy using energy sealing only, without using endostaplers for the pulmonary vessels. During segmentectomy we use energy for the entire hilar and lymph node dissection and sealing of any vessel (vein or artery) of $7 \mathrm{~mm}$ or less (Video 1).
Using energy device sealing in segmentectomy reduces the needs for excessive dissection and manipulation in the lung parenchyma near small pulmonary arteries, and avoids the use of the large footprint vascular endostaplers to seal small arteries. These factors have the potential to reduce the risk for bleeding and post-operative air leak. Moreover, it can save 1-3 endostapler cartridges in most segmentectomies and it also significantly reduces surgical time as there is no swapping of devices during the entire operation; dissection, hemostasis, lymph node harvesting and vessel sealing can be done with the same instrument.

There are some key points for successful sealing of pulmonary vessels with energy devices (Table 2). The first is to choose the right size vessel and to never use it for vessels larger than $7 \mathrm{~mm}$. We recommend using a sterile ruler on vessels where the surgeon is unsure of the size in order to be sure not to seal vessel which are too large (Figure 1). With experience, this becomes unnecessary. When the artery is smaller than $5 \mathrm{~mm}$, it should be sealed with the Min setting with generator set at level " 3 ", and when the vessel is between 5 and $7 \mathrm{~mm}$ it should be sealed using the advanced Hemostasis setting. It is very important to perform a complete circumferential dissection before applying the sealing device and to avoid having other tissue (lung, lymph nodes) between the vessel wall and the instrument. Furthermore, a sufficient dissection will ensure that the whole artery is within the instrument blades. Excessive tissue in between the instrument blades or partial artery sealing can compromise the quality of the seal (Figure 2).

There are a few technical points which can lead to sealing failure or vessel injury. The vessel needs to lie flat in middle of the instrument blades without any folding (Figure 3). When the vessel is in a proper position in between the blades, only one activation should be utilized until the vessel is completely divided. To prevent premature division of the artery, it is very important to avoid tension or torsion for the entire activation. At the end of sealing, the instrument tip can reach temperatures exceeding $200^{\circ} \mathrm{C}$ (18). To avoid a thermal injury for adjacent vessels, airway and parenchyma, it is critically important to maintain a short distance away from the surrounding tissue during activation, and to cool the instrument on the lung to be removed before using it for subsequent dissection. We strongly recommend leaving a significantly long stump (2-5 mm) (Figure 4) to allow easier vascular control in case of sealing failure and to try not to touch the freshly sealed PA stumps with suction or any other instruments following energy division. We do not use clips on the proximal part of the artery branch that 
Table 2 Technical tips and recommendations for successful use of energy devices for pulmonary vessel sealing

Use on arteries $7 \mathrm{~mm}$ or less

Use sterile ruler if the surgeon is unsure of the vessel size

Use proper instrument settings: MIN for vessels $5 \mathrm{~mm}$ and advanced hemostasis for vessels $6-7 \mathrm{~mm}$

Apply on well dissected arteries (skeletonize)

Place the vessel flat in the middle of the instrument blades without folding

Only one activation should be utilized until the vessel is completely divided

Avoid tension or torsion for the entire activation

During activation, try to leave a minimum of $3 \mathrm{~mm}$ of distance between instrument blades and vital structures (phrenic nerve, main PA, bronchus, etc.)

During and after the activation, avoid touching surrounding tissues with the instrument blades

Leave a long enough stump for putting clip in case of failure

Following the sealing, before using the instrument for dissection, cool the blades off on the lung to be removed

Avoid touching the freshly sealed vessel stump with suction or any other instruments

MIN, minimal seating; PA, pulmonary artery.

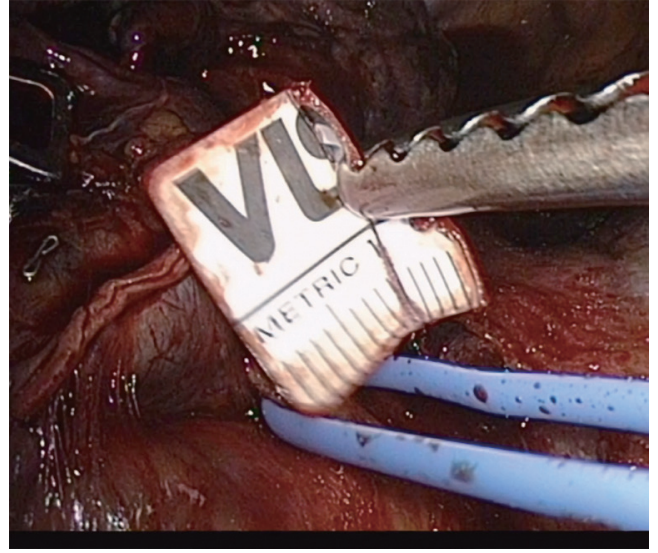

Figure 1 A sterile ruler is used to measure the artery size before applying the sealing device.

has been sealed. Clips can disturb the proper position of the artery in the blades and may interfere with endostaplers later in the operation. Both factors actually increase the risk of bleeding. We use clips only in the rare circumstance when it is extremely hard to achieve the proper position of the vessel within the instrument blades.

In order to reduce a post-operative air leak, after we divide the segmental vessels and bronchus, we use indocyanine green to mark the segment border and divide it by endostaplers (Video 1). We recommend to minimize the use of energy devices for dividing the intersegmental plan as they

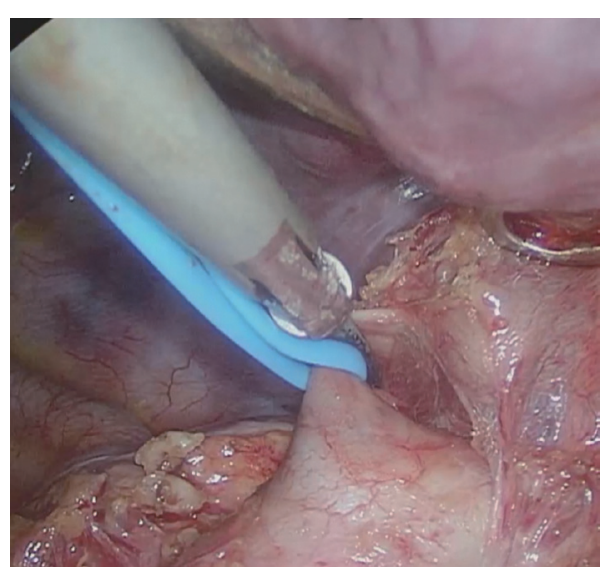

Figure 2 This photo demonstrates incomplete circumferential dissection and excessive tissue in between the instrument blades that can compromise the quality of the seal.

do not seal the lung parenchyma and associated with air leak.

\section{Conclusions}

Using energy devices for sealing of pulmonary vessels $7 \mathrm{~mm}$ or less is both feasible and safe. It significantly aids in simplifying minimally invasive segmentectomy. The learning curve for experienced VATS surgeon, is relatively short and safe. This technique can reduce the risk of bleeding during the dissection and manipulation of small branches and can 


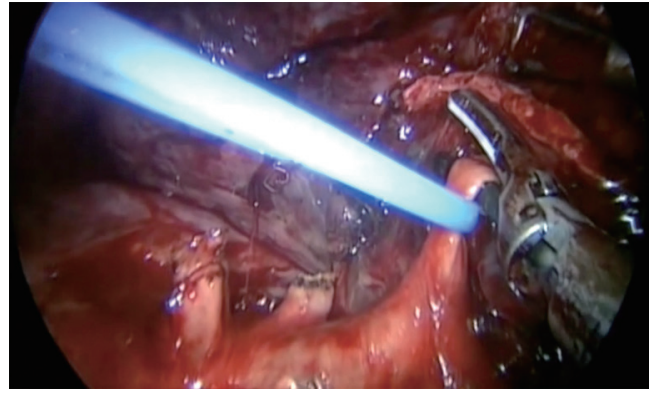

Figure 3 To ensure a good sealing the vessel needs to lie flat in middle of the instrument blades without any folding.

reduce the cost and time of surgery.

\section{Acknowledgments}

Funding: None.

\section{Footnote}

Provenance and Peer Review: This article was commissioned by the Guest Editor (Michel Gonzalez) for the series "VATS Segmentectomy" published in Fournal of Visualized Surgery. The article has undergone external peer review.

Reporting Checklist: The authors have completed the Narrative Review reporting checklist. Available at https:// jovs.amegroups.com/article/view/10.21037/jovs-21-38/rc

Peer Review File: Available at https://jovs.amegroups.com/ article/view/10.21037/jovs-21-38/prf

Conflicts of Interest: Both authors have completed the ICMJE uniform disclosure form (available at https://jovs. amegroups.com/article/view/10.21037/jovs-21-38/coif). The series "VATS Segmentectomy" was commissioned by the editorial office without any funding or sponsorship. The authors have no other conflicts of interest to declare.

Ethical Statement: The authors are accountable for all aspects of the work in ensuring that questions related to the accuracy or integrity of any part of the work are appropriately investigated and resolved. All procedures performed in this study were in accordance with the Helsinki Declaration (as revised in 2013). The manuscript is waived from patient informed consent according to the ethics committee or institutional review board.

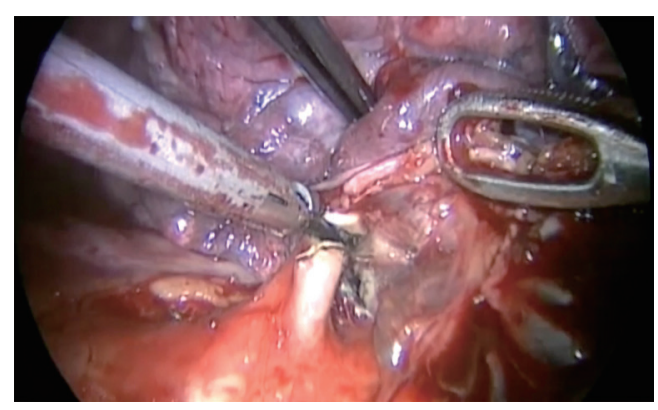

Figure 4 It is important to leave a long stump $(2-5 \mathrm{~mm})$ that allow an easier vascular control in case of sealing failure.

Open Access Statement: This is an Open Access article distributed in accordance with the Creative Commons Attribution-NonCommercial-NoDerivs 4.0 International License (CC BY-NC-ND 4.0), which permits the noncommercial replication and distribution of the article with the strict proviso that no changes or edits are made and the original work is properly cited (including links to both the formal publication through the relevant DOI and the license). See: https://creativecommons.org/licenses/by-nc-nd/4.0/.

\section{References}

1. Dai C, Shen J, Ren Y, et al. Choice of Surgical Procedure for Patients With Non-Small-Cell Lung Cancer $\leq 1 \mathrm{~cm}$ or $>1$ to $2 \mathrm{~cm}$ Among Lobectomy, Segmentectomy, and Wedge Resection: A Population-Based Study. J Clin Oncol 2016;34:3175-82.

2. Khullar OV, Liu Y, Gillespie T, et al. Survival After Sublobar Resection versus Lobectomy for Clinical Stage IA Lung Cancer: An Analysis from the National Cancer Data Base. J Thorac Oncol 2015;10:1625-33.

3. Mehta H, Osasona A, Shan Y, et al. Trends and Outcomes of Thoracoscopic Lobectomy or Segmentectomy: A National Surgical Quality Improvement Project Analysis. Semin Thorac Cardiovasc Surg 2018;30:350-9.

4. Gazala S, Hunt I, Valji A, et al. A method of assessing reasons for conversion during video-assisted thoracoscopic lobectomy. Interact Cardiovasc Thorac Surg 2011;12:962-4.

5. Lacin T, Batirel HF, Ozer K, et al. Safety of a thermal vessel sealer on main pulmonary vessels. Eur J Cardiothorac Surg 2007;31:482-5; discussion 485.

6. Lesser TG, Wolfram F, Boltze C. Sealing of pulmonary arteries with LigaSure: in vivo and ex vivo examinations. J Thorac Cardiovasc Surg 2013;145:1525-8. 
7. Yoshiya T, Mimae T, Tsubokawa N, et al. The differences in histological changes among pulmonary vessels divided with an energy device. Interact Cardiovasc Thorac Surg 2018;27:372-8.

8. Okada M, Miyata Y, Takamochi K, et al. Prospective feasibility study of sealing pulmonary vessels with energy in lung surgery. J Thorac Cardiovasc Surg 2019;157:388-95.

9. Nicastri DG, Wu M, Yun J, et al. Evaluation of efficacy of an ultrasonic scalpel for pulmonary vascular ligation in an animal model. J Thorac Cardiovasc Surg 2007;134:160-4.

10. Tanaka T, Ueda K, Hayashi M, et al. Clinical application of an ultrasonic scalpel to divide pulmonary vessels based on laboratory evidence. Interact Cardiovasc Thorac Surg 2009;8:615-8.

11. Toishi M, Yoshida K, Agatsuma H, et al. Usefulness of vessel-sealing devices for $\leq 7 \mathrm{~mm}$ diameter vessels: a randomized controlled trial for human thoracoscopic lobectomy in primary lung cancer. Interact Cardiovasc Thorac Surg 2014;19:448-55.

12. Liberman M, Khereba M, Goudie E, et al. Pilot study of pulmonary arterial branch sealing using energy devices in an ex vivo model. J Thorac Cardiovasc Surg 2014;148:3219-23.

13. Liberman M, Khereba M, Nasir B, et al. Pulmonary Artery

doi: $10.21037 /$ jovs-21-38

Cite this article as: Katz A, Liberman M. Energy devices for pulmonary artery sealing in video-assisted thoracoscopic surgery (VATS) segmentectomy: literature review and surgical technique. J Vis Surg 2022;8:35.
Sealing Using the HARMONIC ACE+ Shears for VideoAssisted Thoracoscopic Surgery Lobectomy. Ann Thorac Surg 2015;100:898-903; discussion 903-4.

14. Goudie E, Khereba M, Tahiri M, et al. Pulmonary Artery Sealing With an Ultrasonic Energy Device in VideoAssisted Thoracoscopic Surgery Lobectomy: An Animal Survival Study. Ann Thorac Surg 2016;102:1088-94.

15. Goudie E, Thiffault V, Jouquan A, et al. Pulmonary artery sealing with ultrasonic energy in open lobectomy: A phase I clinical trial. J Thorac Cardiovasc Surg 2017;153:1600-7.

16. Goudie E, Oliveira RL, Thiffault V, et al. Phase 1 Trial Evaluating Safety of Pulmonary Artery Sealing With Ultrasonic Energy in VATS Lobectomy. Ann Thorac Surg 2018;105:214-20.

17. Liberman M, Goudie E, Morse C, et al. Prospective, multicenter, international phase 2 trial evaluating ultrasonic energy for pulmonary artery branch sealing in video-assisted thoracoscopic surgery lobectomy. J Thorac Cardiovasc Surg 2019. doi: 10.1016/j.jtcvs.2019.09.061.

18. Goudie E, Oliveira R, Thiffault V, et al. Heat production during pulmonary artery sealing with energy vessel-sealing devices in a swine model. Interact Cardiovasc Thorac Surg 2020;31:847-52. 